\title{
Incidence and predictors of neonatal mortality among neonates admitted in Amhara regional state referral hospitals, Ethiopia: prospective follow up study
}

Banchigizie Adane Mengistu ${ }^{1 *+}$, Ayenew Engida Yismaw ${ }^{2 \dagger}$, Zelalem Nigussie Azene ${ }^{3 \dagger}$ and Muhabaw Shumye Mihret ${ }^{2 \dagger}$

\begin{abstract}
Background: Globally, about 2.7 million neonates die annually and more than 99\% of these deaths happened in developing countries. Although most neonatal deaths are preventable and attempts had been taken to tackle these deaths, an aggregate of 30 neonatal deaths per 1000 live births had been reported in Ethiopia. In this regard, identifying the predictors could be an important step. However, evidence on the incidence and predictors of neonatal mortality has been limited in Ethiopia, in the study area in particular. Even the available studies were limited in scope and were retrospective or cross section in nature. Thus, this study is aimed at assessing the incidence and predictors of neonatal mortality among neonates admitted in Amhara regional state referral hospitals, Ethiopia..
\end{abstract}

Method: A multi center prospective follow up study was conducted on 612 neonates admitted in Amhara region referral hospitals from July 01 to August 30, 2018. A simple random sampling technique was used to select three of all referral hospitals in the study settings and all neonates admitted in the selected hospitals were included. Data were entered into Epi info version 7.0 and exported to STATA 14.0 for analysis. Cox proportional hazard regression model was fitted to identify predictors of neonatal mortality. Crude and Adjusted hazard ratio with 95\% confidence interval was computed and variables' statistical significance was declared based on its AHR with $95 \% \mathrm{Cl}$ and $p$-value $\leq 0.05$.

Result: Overall, 144 (18.6\%) neonates died with a total person-time of 4177.803 neonate-days which is equivalent to the neonatal mortality rate of 186 per 1000 admitted neonates with $95 \% \mathrm{Cl}(157,219)$. The incidence rate of neonatal mortality was 27 per 1000 admitted neonates with $95 \% \mathrm{Cl}(23,33)$. Maternal age $\geq 35$ years ( $\mathrm{AHR}=2.60 ; 95 \% \mathrm{Cl}: 1.44,4.72$ ), mothers unable to read and write (AHR $=1.40 ; 95 \% \mathrm{Cl}: 1.23,2.44)$, multiple pregnancy (AHR $=3.96 ; 95 \% \mathrm{Cl}: 2.10,7.43$ ) and positive maternal HIV status (AHR $=6.57 ; 95 \% \mathrm{Cl}: 2.53,17.06)$ were predictors of neonatal mortality.

(Continued on next page)

\footnotetext{
* Correspondence: banchimu4@gmail.com

${ }^{\dagger}$ Banchigizie Adane Mengistu, Ayenew Engida Yismaw, Zelalem Nigussie Azene and Muhabaw Shumye Mihret contributed equally to this work.

${ }^{1}$ Teda Health Science College, Amhara Regional Health Bureau, Department of Midwifery, Po. Box 196, Gondar, Ethiopia

Full list of author information is available at the end of the article
}

(c) The Author(s). 2020 Open Access This article is licensed under a Creative Commons Attribution 4.0 International License, which permits use, sharing, adaptation, distribution and reproduction in any medium or format, as long as you give appropriate credit to the original author(s) and the source, provide a link to the Creative Commons licence, and indicate if changes were made. The images or other third party material in this article are included in the article's Creative Commons licence, unless indicated otherwise in a credit line to the material. If material is not included in the article's Creative Commons licence and your intended use is not permitted by statutory regulation or exceeds the permitted use, you will need to obtain permission directly from the copyright holder. To view a copy of this licence, visit http://creativecommons.org/licenses/by/4.0/. The Creative Commons Public Domain Dedication waiver (http://creativecommons.org/publicdomain/zero/1.0/) applies to the data made available in this article, unless otherwise stated in a credit line to the data. 
(Continued from previous page)

Conclusion: In this study, the neonatal mortality rate was higher than the national figure. Its most predictors were found to be modifiable. Thus, the stakeholders would better consider the aforementioned predictors to decrease this higher burden.

Keywords: Amhara region, Neonatal intensive care unit, Neonatal mortality incidence rate, Neonatal death, Predictors, Survival of neonates

\section{Background}

Neonatal Mortality Incidence Rate (NMIR) is a probability of dying during the first 28 days of life and expressed per 1000 admitted neonates [1, 2]. The neonatal period commences at birth and ends at 28 completed days after birth and this period is the most vulnerable time for a child's survival [3-5]. This period is also further classified as early (the first 7 days) and late (the remaining 21 days) neonatal period and majority neonatal mortality occur in the early neonatal period $[4,6,7]$.

Neonatal mortality (NM) is a major global public health challenge $[5,8,9]$. Approximately 2.7 million neonates worldwide each year die in the first month of life and most of these deaths happen in developing countries $[6,10]$. NM accounts for about $44 \%$ of under-five deaths and more than $99 \%$ of these deaths occur in middle or low-income countries [5, 6]. According to United Nations International Children's Emergency Fund (UNICEF) 2018 report, Neonatal Mortality Rate (NMR) in the globe and the least developed countries was 19 and 26 per 1000 live birth respectively [1]. Accordingly, the problem is much higher in South Asia (SA), West and Central Africa (WCA), and sub-Saharan Africa (SSA) [1]. Similarly, NMR in Ethiopia is higher (i.e., reported to be 30 per 1000 live births) and the largest figure was recorded at Amhara national regional state where it was estimated to be about 47 per 1000 live birth $[2,11]$.

To alleviate these problems, efforts have been made globally as well as nationally. For instance, it was included in and remained "unfinished agenda" of Millennium Development Goals (MDGs) which was extended to Sustainable Development Goals (SDGs) [9, 12]. Hence, target 2 of SDG 3 is planned to end preventable deaths of newborns by all countries aiming to reduce neonatal mortality to at least as low as 12 per 1000 live births by 2030 [9]. In line with this, Ethiopia has planned to reduce NMR from 28 in 2015/16 to 10 per 1000 live births by 2019/2020 [13]. Consequently, the NMR has went down from 36 deaths per 1000 live births in 1990 to 19 in 2015, and the number of neonatal deaths declined from 5.1 million to 2.7 million globally [10]. Generally, the number of children dying before the age of five has declined from 9.9 million in 2000 to 5.6 million in 2016 [3]. However, the proportion of under-five deaths in the newborn period has increased from 41 to
46\% between 2000 and 2016 globally [3]. Moreover, the decline in neonatal mortality (47\%) from 1990 to 2015 has been slower than that of post-neonatal under-five mortality (58\%) globally [3]. The scenario is similar in Ethiopia, where NMR has decreased from 49 in 2000 to 29 in 2016 as to EDHS reports [2]. However, the NMR decrement in Ethiopia is also much slower than that of post neonatal under-five mortality (41\% compared with 85\%) from 2000 to2016 [2]. Thus, identifying the causes of such challenges is one import part of the efforts. The previously identified causes of neonatal mortality such as hypothermia, neonatal sepsis, respiratory distress syndrome, and prenatal asphyxia may vary across settings and over time [12, 14-19].

The high NMR reflects the poor quality of care service especially during the perinatal period in a given country or region [3]. Hence, its implication reminds the concerned bodies to evaluate their respective health care system and to develop effective strategies. To design such evidence-based and problem oriented strategies which may be effective - for instance, in reducing delays in accessing obstetric and neonatal health care services such as improving community awareness of neonatal death risk factors, cultivating practices towards birth preparedness and complication readiness plan, reducing transportation barriers, preventing financial barriers, strengthening referral mechanisms, reducing barriers to good health-seeking behaviors, and enhancing the level of health facility's preparedness and readiness for neonatal obstetric emergencies, the role of accurate contemporize information is compulsory for combating the burden thereby for achieving the SDG. Thus, methodologically sound and representative investigations need to be done by far, more importantly in the settings where high NMR has been reported, and the Amhara national regional state is an example. Having this insight, this study was conducted to assess incidence and predictors of neonatal mortalities among neonates admitted in Amhara region referral hospitals, Northern Ethiopia, 2018.

\section{Methods}

A multicenter prospective follow up study was conducted in referral hospitals which are located in Amhara national regional state, Northern Ethiopia from July 01 to August 30/2018. 
Amhara national regional state is the second-largest and populous region in Ethiopia [2]. The region has five referral hospitals namely University of Gondar comprehensive specialized hospital (UoGCSH), Felege-Hiwot comprehensive specialized hospital (FHCSH), Dessie referral hospital (DRH), Debre-Markos referral hospital $(\mathrm{DMRH})$ and Debre-Birhan referral hospital (DBRH). Among these, Dessie, Felegehiwot and Debre-Markos referral hospitals were selected randomly.

Thereafter, we included all neonates who had been admitted in the corresponding neonatal intensive care unit (NICU) of each selected hospital.

We calculated the sample size for this study by using STATA version 14 with the following assumptions: the probability of neonatal death- 0.88 and the hazard ratio of the predictor breast feeding-7.5 as reported in a previous study done in Tigray, Northern Ethiopia [12]; power-80\%; confidence level-95\%; margin of error- $4 \%$ and non-response rate-10\%. Accordingly, the final sample size was obtained to be 631 .

The number of sample size for each selected hospital was allocated proportionally based on the number of previous cases flow. All recruited study participants had been followed till the outcome of interest (i.e. either death or censure) appeared. Data were collected through face to face interview and chart review. The outcome variable of the study was admission outcome which was dichotomized as death (coded as ' 1 ') or censored (coded as ' 0 ') whereas, the explanatory variables included sociodemographic, obstetrics, medical, health service and neonatal related factors. These include maternal age, mother's educational status, husband's educational status, marital status, religion, maternal occupation, husband's occupation, ethnicity, residence, distance from nearest health facility, premature rupture of membrane (PROM), delivery complication, mode of delivery, parity, Infant of Diabetic Mother (IDM), history of previous dead fetus, polygamous household, number of ANC visit, HIV status of mother, tetanus toxoid vaccine, multiple pregnancies, birth interval, skilled birth attendant, place of ANC visit, place of delivery, birth weight, congenital abnormality, fetal presentation, 1st minute APGAR score, 5th minute APGAR score, time of initiation of breastfeeding, hypothermia, neonatal sepsis, respiratory distress syndrome (RDS), jaundice, perinatal asphyxia (PNA), anemia, hypoglycemia, prematurity, neonatal sex, age on admission, neonatal complication, feeding option, cry at birth and weight at admission.

\section{Operational definitions \\ Time}

the period from starting of observation until the occurrence of outcome of observation (death or censored).

\section{Death}

In this study, death referred to the study subject who had experienced the interest of event (had died) during the observation period and labeled as (1).

\section{Censored}

In this paper, censored is referred to the study subject who had not experienced death during the follow-up period. These included neonates who had lost follow up, referred to other health institution, discharged with improvement or stayed with admission beyond 28 days of neonatal age.

\section{Data collection, quality control mechanism, processing, and analysis}

Data were collected through face to face interview and chart review using structured questionnaire and checklists which were adapted from related literature [12, 17]. The questionnaire was prepared in English and translated into Amharic and then re-translated back to English.

About six health personnel had been recruited for the data collection process. These included three professional diploma midwives for data collection and another three professional first degree midwives for supervision. A training of 2 days had been provided for the data collectors and supervisors regarding the ethical issues, general approaches, strategies to minimize information bias, etc. Pretest then had been conducted on the $5 \%$ of the total sample sizes in the unselected referral hospital prior to the commencement of actual data collection. During the data collection period, all neonates admitted in NICU with their mothers were enrolled in the first month and then had been followed until the occurrence of the outcome of interest. After putting aside the baseline data on socio-demographic factors; obstetrics related factors; health service-related factors and neonatal factors on the first day of enrollment, gathering data on neonatal related factors had been carried out daily throughout the follow-up period (i.e. from the time of admission to the 28 days of neonatal age) or till the neonates had either experienced the interest of event (i.e. death or censored). In the mean time, data collectors had been supervised, samples of respondents reinterviewed and the results then cross-checked.

Moreover, each data collector had checked the questionnaires and the checklists for completeness before leaving each study participant. Each questionnaire and checklist was then reviewed daily by supervisors and the principal investigator to check for completeness and clarity. Data entry format template, using Epi info version 7 , was produced and data were entered.

Data clean up was done before analysis. Data were checked, coded and entered to EPI INFO version 7 then 
it was exported to STATA version 14 for analysis. Both descriptive and analytical statistical procedures were utilized. Descriptive statistics like percentage, median, interquartile range (IQR), mean and standard deviation were employed. Tables and fingers were also used for data presentation.

Proportional hazard assumption was checked both graphically (Fig. 1)) and hypothetically using a hypothesis test called Shoenfield residual test (global test). Accordingly, Shoenfield residuals test showed that the proportional hazard assumption was satisfied. After the proportional hazard assumption had been checked, both bivariate and multivariable Cox proportional hazard regression analysis was computed. All variables having $P$ value $\leq 0.2$ and with no missing values in the bivariable analysis had been then further fitted to the final model to identify independent predictors of neonatal mortality and finally the variables which have independent association with outcome variable were identified on the basis of AHR, with $95 \% \mathrm{CI}$ and $p$-value $\leq 0.05$. In addition, Kaplan Meier Estimator curve was used to estimate failure time of neonate (Fig. 2), and Cox-Snell residual test was utilized to check the goodness of model fitness (Fig. 3).

\section{Result}

\section{Socio-demographic and economic characteristics}

A total of 612 mother-neonate pairs were included in the study making a response rate of $97 \%$. Majorities (78.1\%) of the mothers of neonates were in the age group of 20-34 years with a median of 27 years with $\mathrm{IQR}=24-31$. More than half $(62.58 \%)$ of the respondents were urban dwellers and nearly nine-tenths (89.22\%) of the respondents were Orthodox Christian by religion. Almost all (96.9\%) of the mothers were married and about 594 (97.06\%) of respondents belong to Amahara Ethnicity. Nearly four-fifth (77.1\%) of respondents' family earned less than $\$ 139$ monthly. About one-third (33.82\%) of mothers had not been able to read and write. More than half $(58.17 \%)$ of the mothers and more than one-third $(38.45 \%)$ of the husbands were housewives and farmers by occupation respectively (Table 1 ).

\section{Obstetrics and medical-related characteristics of the respondent}

More than two-fifth (42.97\%) and nearly one-fourth $(12.9 \%)$ of mothers were primiparous and grandmultiparous respectively. Regarding birth spacing between the previous and the indexed pregnancy, majority $(83.7 \%)$ of respondents had an inter-pregnancy interval of $\geq 24$ months. More than a quarter $(29.24 \%)$ of the respondents gave birth through cesarean section. All (100\%) parents of neonates reported to have monogamous sexual relationship. Substantial member (93.79\%) of the mothers of neonates had ANC follow up, whereas significant proportion $(53.66 \%)$ of the mothers had incomplete ANC visit in the indexed pregnancy. Almost one-fifth $(19.1 \%)$ of the mothers of neonates had a history of PROM, whereas more than one-tenth (10.5\%) of the mothers conceived multiple fetuses in the indexed pregnancy. About 18 (2.94\%) and 108 (17.65\%) of the mothers of the neonates had Diabetes Mellitus in the indexed pregnancy and history of a previous dead fetus respectively (Table 2).

\section{Health service-related characteristics}

Out of 397 birth attendants with identified professions, about 171 (43.07\%) of them were midwives. Among 591 health facility deliveries, nearly two-third (68.19\%) of them were undertaken at hospitals. More than half (60.29\%) of the mothers of neonates visited health centers for ANC follow up during the indexed pregnancy (Table 3).

\section{Fetal and neonatal related characteristics}

The substantial proportion (59.6\%) of neonates were males by sex and more than half $(62.07 \%)$ of the neonatal weight ranged between $2.5 \mathrm{~kg}$ and $4 \mathrm{~kg}$ with mean \pm SD weight of $2.56( \pm 0.766)$. The majority $(91.50 \%)$ of the neonates were delivered with the normal presentation. The first and fifth minute Apgar score of the neonates were found in the range of 2 to 9 with a mean \pm SD of $6.31( \pm 1.737)$ and 4 to 10 with mean of $7.63( \pm 1.437)$ respectively. About $568(92.81 \%)$ of the mothers of the neonates had a plan for exclusive breastfeeding, whereas about $40(6.54 \%)$ of the respondents intended to practise mixed infant feeding. Among mothers with exclusive breast feeding plan, nearly half (48.68\%) of $\mathrm{t}$ them had initiated neonatal feeding within $1 \mathrm{~h}$ of birth. More than two-third (69.3\%) of the neonates had been admitted in NICU within $24 \mathrm{~h}$ of birth. About 186 (30.4\%) of the neonates had experienced complication at the time of birth and nearly one - third (60.3\%) of neonates cried at birth (Table 4).

The top three reasons for neonatal admission at the NICU in the referral hospitals in Amhara national regional state were neonatal sepsis (27.3\%), hypothermia (15.7\%) and prematurity (13.5\%) (Fig. 4).

\section{Neonatal mortality incidence rate and time to death}

Admitted neonates had been followed up for a total of 4177.803 neonate-days. The proportion of neonatal death among admitted neonates was obtained to be $18.6 \%$ with $95 \%$ CI $(15.7,21.9)$ which is equivalent to the NMR of 186 per 1000 admitted neonates with 95\% CI $(157,219)$. Whereas, the neonatal mortality incidence rate (NMIR) was calculated to be 27 per 1000 admitted neonates with $95 \%$ CI $(23,33)$. 


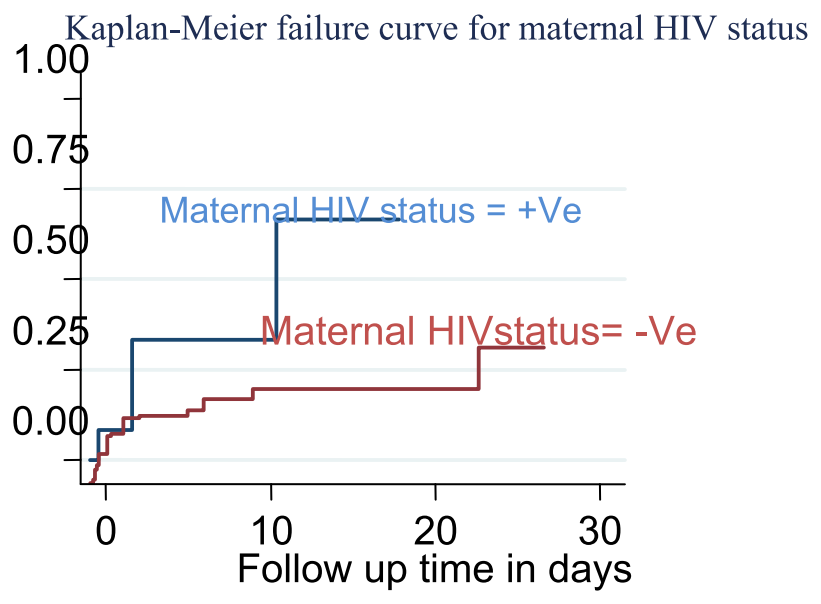

Kaplan-Meier failure curve by maternal age

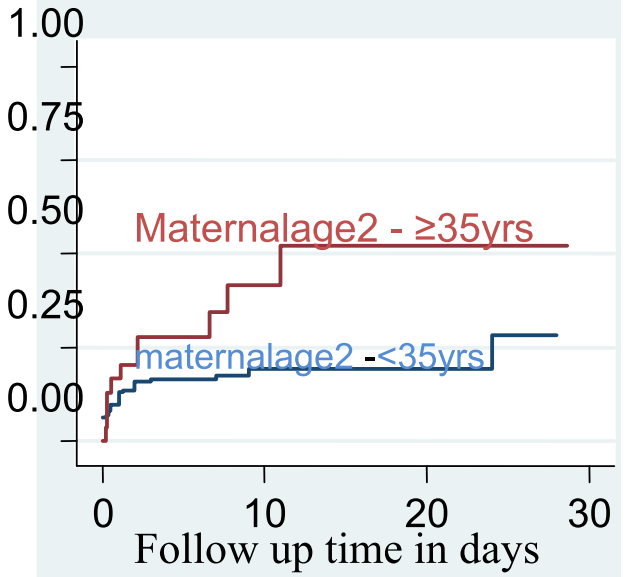

Fig. 1 Kaplan-Meier failure curve for neonates admitted in NICU by maternal HIV status and maternal age respectively at Amhara referral

Among dead neonates, more than half (56.14\%) of them have died within $24 \mathrm{~h}$ and about nine-tenth (90.35\%) died in the early neonatal period. The overall cumulative probability of death was $28.89 \%$ with $95 \%$ CI $(23.57,35.12)$. The cumulative probabilities of death at the end of the first day and within the first 7 days were 10.85 and $20.30 \%$ respectively (Table 5 ).

As far as the influence of each primary diagnosis to neonatal death is concerned, low birth weight had attributed to $80(70.18 \%)$ of neonatal deaths followed by preterm birth to 69 (60.53\%), RDS to 47 (41.23\%), neonatal sepsis to $28(24.56 \%)$, PNA and PROM each to $15(13.16 \%)$, hypoglycemia to 8 (7.02\%), anemia to $7(6.14 \%)$, MAS to 6 (5.26) and other minors such as congenital anomalies, jaundice, etc. to 7 (6.14\%) neonatal deaths.

\section{Predictors of neonatal mortality}

Initially, all variables had been entered to the bivariate Cox proportional hazard regression model. Based on the bivariate Cox proportional hazard regression analysis, maternal age, residence, mother's educational status, number of ANC visit, TT vaccination, type of pregnancy, delivery complication, fetal presentation, maternal HIV status, parity, cry at birth, neonatal age at admission, neonatal sepsis, neonatal sex, and history of stillbirth had been associated with NM. Furthermore, variables with $P$-value of $\leq 0.2$ in the bivariate analysis and with no missing values had been fitted to the final model. Ultimately, maternal age, maternal educational status, multiple pregnancies, and maternal HIV status had remained independent predictors of NM in the multivariable Cox proportional hazard regression analysis. 


\section{Kaplan-Meier failure curve}

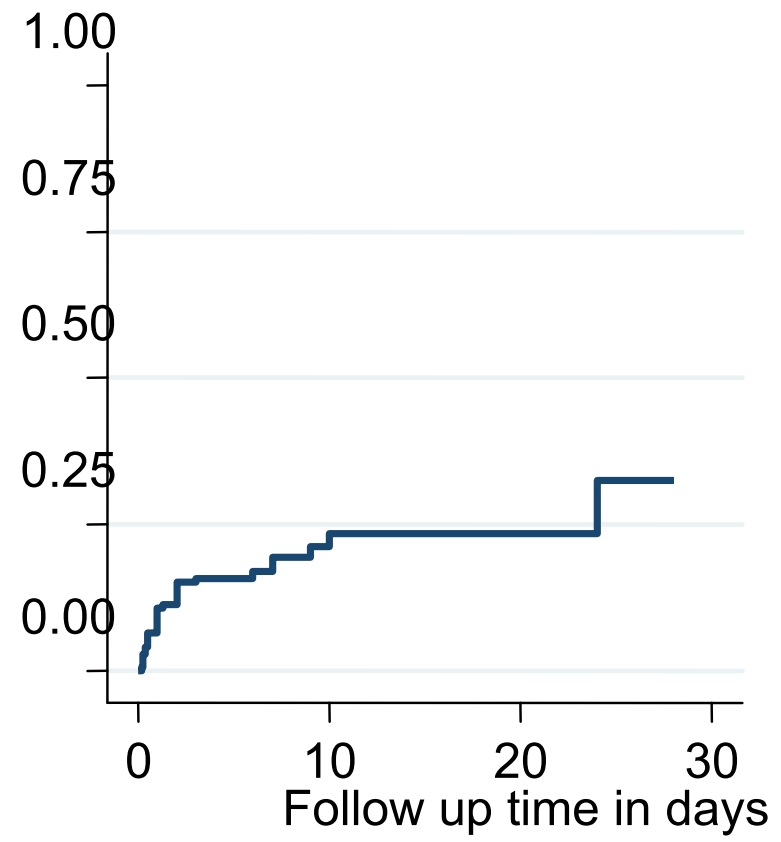

Fig. 2 Kaplan-Meier failure curve for neonates admitted in NICU at Amhara region referral hospital. The graph shows the proportion of neonatal death during follow up time
Accordingly, the risk of NM among neonates who born to mothers with advanced age was 2.60 times higher as compared to their counterparts $(\mathrm{AHR}=2.60$; 95\% CI:1.44, 4.72). Likewise, the risk of mortality for neonates born to mothers who are unable to read and write was 1.40 times higher than that of neonates whose mothers are able to read and write (AHR $=1.40 ; 95 \% \mathrm{CI}$ : $1.23,2.44)$. Equally, multiple pregnancies increased the risk of NM by 3.96 folds as compared to the counterpart $(\mathrm{AHR}=3.96 ; 95 \% \mathrm{CI}: 2.10,7.43)$. Similarly, neonates born to HIV positive mothers were 6.57 times more likely to experience death during the neonatal period than those neonates who born to sero-negative mothers $(\mathrm{AHR}=6.57: 95 \%$ CI: 2.53, 17.06) (Table 6).

\section{Discussion}

Neonatal mortality rate remains unacceptably high in most of resource limited countries including Ethiopia although under-five mortality has been declining substantially since 2000 [20]. Moreover, the proportion of neonatal deaths over under-five deaths is increasing time to time despite the governmental commitments. For example, in Ethiopia, the neonatal mortality rate was reported to be 29 per 1000 live births as of EDHS 2016 and was targeted to reduce to 10 per 1000 live births in 2019/20 in line with the target two of SDG 3 [9]. Paradoxically, the magnitude reported to be elevated (i.e. 30 per 1000 live births) according to mini EDHS 2019 [11].

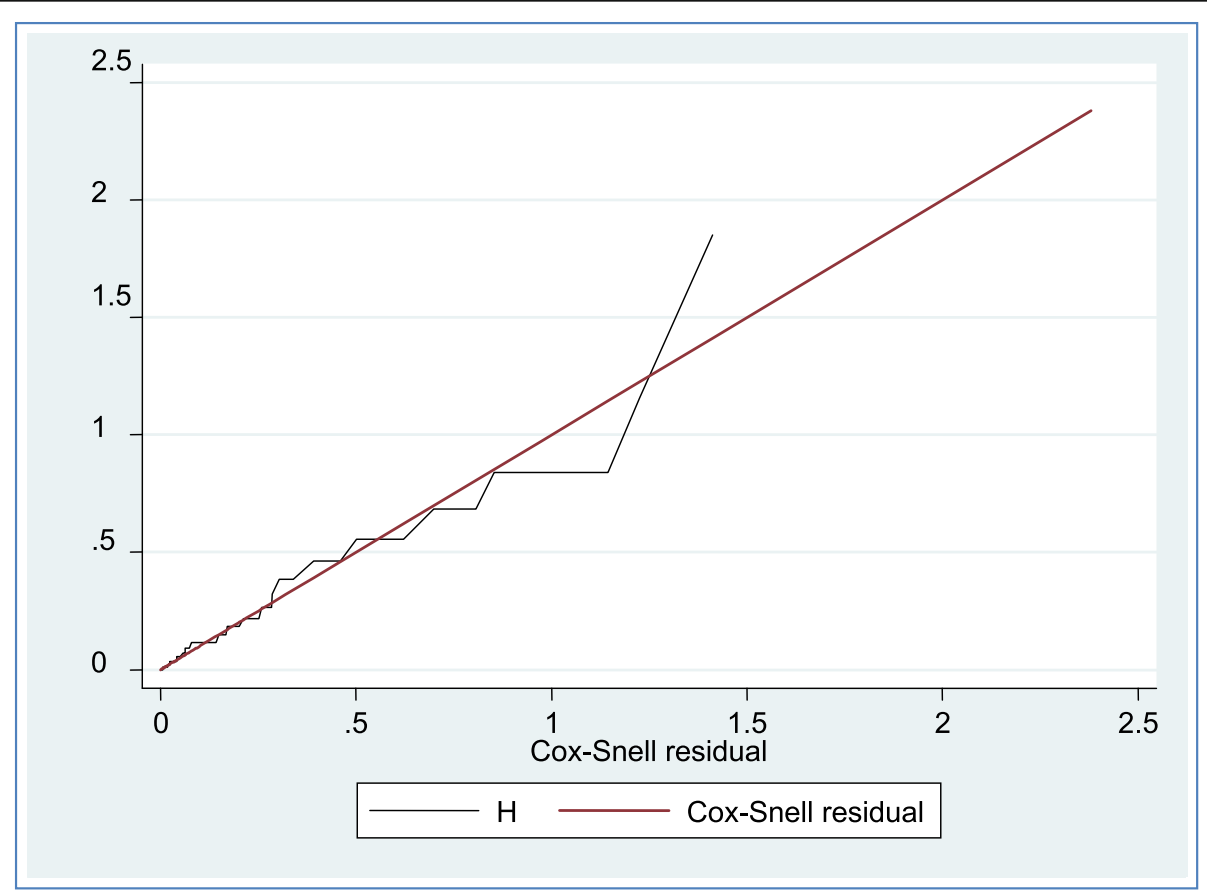

Fig. 3 Cox-Snell residual Nelson- Alen cumulative hazard graph on neonates admitted in NICU at Amhara referral hospital, Northwest Ethiopia, 2018 for the goodness of model fitness which shows the hazard function follows the $45^{\circ}$ closed to the baseline 
Table 1 Socio-demographic and economic characteristics of parents of neonates admitted in Amhara Referral hospitals Northern Ethiopia $(n=612)$

\begin{tabular}{|c|c|c|}
\hline Variables & Number & Percent \\
\hline \multicolumn{3}{|l|}{ Current Maternal Age } \\
\hline 18-19years & 26 & 4.25 \\
\hline 20-34 years & 478 & 78.10 \\
\hline$\geq 35$ years & 108 & 17.65 \\
\hline \multicolumn{3}{|l|}{ Marital status } \\
\hline married & 593 & 96.9 \\
\hline unmarried & 19 & 3.1 \\
\hline \multicolumn{3}{|l|}{ Maternal Occupation } \\
\hline Housewife & 356 & 58.17 \\
\hline Government employee & 141 & 23.04 \\
\hline Merchant & 77 & 12.5 \\
\hline Others $^{a}$ & 38 & 6.21 \\
\hline \multicolumn{3}{|c|}{ Husband Occupation ( $n=593$ ) } \\
\hline Farmer & 228 & 38.45 \\
\hline Government employee & 159 & 26.81 \\
\hline Merchant & 133 & 22.43 \\
\hline Others ${ }^{b}$ & 73 & 12.31 \\
\hline \multicolumn{3}{|l|}{ Maternal educational status } \\
\hline Unable to read \& write & 207 & 33.82 \\
\hline Able to read \& write & 30 & 4.9 \\
\hline Primary school(1-8) & 107 & 17.48 \\
\hline Secondary school (9-12) & 76 & 12.42 \\
\hline Higher education (>12) & 192 & 31.37 \\
\hline \multicolumn{3}{|c|}{ Husband educational status ( $n=593$ ) } \\
\hline Unable to read \& write & 177 & 29.85 \\
\hline Able to read \& write & 65 & 10.96 \\
\hline Primary school & 63 & 10.62 \\
\hline Secondary school & 89 & 15.01 \\
\hline Higher education & 199 & 33.56 \\
\hline \multicolumn{3}{|c|}{ Family monthly income (in US\$) } \\
\hline$<139$ & 472 & 77.1 \\
\hline$\geq 139$ & 140 & 22.9 \\
\hline \multicolumn{3}{|l|}{ Religious } \\
\hline Orthodox & 546 & 89.22 \\
\hline Muslim & 66 & 10.78 \\
\hline \multicolumn{3}{|c|}{ Distance to health facility in hours (on foot) } \\
\hline$\leq 2 \mathrm{~h}$ & 586 & 95.8 \\
\hline$>2 \mathrm{~h}$ & 26 & 4.2 \\
\hline \multicolumn{3}{|l|}{ Ethnicity Group } \\
\hline Amhara & 594 & 97.06 \\
\hline Others $^{c}$ & 18 & 2.94 \\
\hline
\end{tabular}

${ }^{a}$ Student, Daily laborer, House worker \& Private employee, ${ }^{b}$ Daily laborer, Student, Private employee \& Car driver, 'Agew, Oromo \& Binshangul Gumz
Table 2 Obstetric and medical-related factors among mothers of neonates admitted in Amhara region referral Hospitals, Northern Ethiopia, $2018(n=612)$

\begin{tabular}{|c|c|c|}
\hline Variables & Number & Percent \\
\hline \multicolumn{3}{|l|}{ Parity } \\
\hline 1 & 263 & 42.97 \\
\hline $2-4$ & 270 & 44.12 \\
\hline$\geq 5$ & 79 & 12.91 \\
\hline \multicolumn{3}{|c|}{ Interpregnancy interval in months $(n=332)$} \\
\hline$<24$ & 51 & 15.4 \\
\hline $24-120$ & 278 & 83.7 \\
\hline$>120$ & 3 & 0.9 \\
\hline \multicolumn{3}{|c|}{ Delivery complication in the indexed pregnancy } \\
\hline Yes & 323 & 52.78 \\
\hline No & 289 & 47.22 \\
\hline \multicolumn{3}{|l|}{ Mode of delivery } \\
\hline Cesarean section & 179 & 29.25 \\
\hline Spontaneous vaginal delivery & 357 & 58.33 \\
\hline Forceps delivery & 11 & 1.80 \\
\hline Vacuum delivery & 34 & 5.56 \\
\hline Vaginal with episiotomy & 27 & 4.41 \\
\hline Assisted breech delivery & 4 & 0.65 \\
\hline \multicolumn{3}{|l|}{ Maternal HIV status } \\
\hline Positive & 15 & 2.5 \\
\hline Negative & 597 & 97.5 \\
\hline \multicolumn{3}{|c|}{ Tetanus toxoid vaccine for the index pregnancy } \\
\hline Yes & 504 & 82.4 \\
\hline No & 108 & 17.6 \\
\hline \multicolumn{3}{|l|}{ Number of ANC visit $(n=574)$} \\
\hline One visit & 16 & 2.79 \\
\hline Two visit & 109 & 18.99 \\
\hline Three visit & 183 & 31.88 \\
\hline Four and more visit & 266 & 46.34 \\
\hline
\end{tabular}

Hence, it is among major current public health challenges which require appropriately designed strong studies to generate accurate and representative information so that stakeholders can apply evidence based interventions. Eventhough some studies had been conducted on neonatal mortality and predictors in Ethiopia, no large scale study including all referral hospitals of Amhara region was carried out, as to the investigators deep review. In addition, no prospective follow up studies had been done on neonatal death in the study area. Therefore, this study is aimed to address these gaps particularly to assess NMR, time to death and predictors among admitted neonates in referral hospitals in Amhara national regional state to provide basic information for any intervention aimed at improving neonatal health. . 
Table 3 Health service related factors of respondents in Amhara region referral hospitals, Northern Ethiopia, $2018(n=612)$

\begin{tabular}{lll}
\hline Variables & Numbers & Percent (\%) \\
\hline Birth attendants $(n=397)$ & 34 & 8.56 \\
Diploma midwifery & 110 & 27.71 \\
BSC midwifery & 27 & 6.80 \\
MSC midwifery & 16 & 4.03 \\
IEOS & 32 & 8.06 \\
Intern & 154 & 38.79 \\
MD/GP and above & 24 & 6.05 \\
Others & \\
Place of delivery & & \\
Home & 21 & 3.43 \\
Health facility & 591 & 96.57 \\
Level of health facility for place of delivery $(n=591)$ & \\
Health post & 3 & 0.51 \\
Health center & 151 & 25.55 \\
Primary hospital & 93 & 15.74 \\
Referral hospital & 310 & 52.45 \\
Private clinic & 34 & 5.75 \\
Place of ANC visit $(n=574)$ & & 6.99 \\
Health post & 28 & \\
Health center & 369 & \\
Hospital & 122 & \\
Private & 55 & \\
\hline
\end{tabular}

IEOS Integrated Emergency in Obstetrics and Surgery, MD Medical Doctor, GP General Practitioner

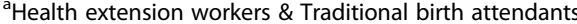

The magnitude of NMR is higher than the national figure and the highest probability of neonatal death has been recorded in the early neonatal period. The risk of NM was higher among neonates whose mothers were HIV positive, uneducated, advance aged and gravid of multiple fetuses in the indexed pregnancy.

In the current study, NMR was 186 per 1000 admitted neonates. This finding is comparable with the study conducted in Wolaita Sodo referral hospital in southern Ethiopia (173) [21] and sub-urban hospital in Cameron (157) [22].

However, the current study findings demonstrated that the magnitude of NMR is higher than the result of other previous studies done in Iran- 91 [19], China- 12 [23], Suriname- 129 [24], Indonesia- 52 [25], Nigeria- 41 [7], Burkina Faso- 46.3 [26], Sudan- 30 [15], UNICEF 2018 report [1] and EDHS 2016 report- 29 [2]. It is also higher as compared to local studies conducted in various part of Ethiopia such as the Somali region of Ethiopia57 [27], Dilchora referral hospital in Dire Dawa- 114.4 [28], Jimma Zone- 35.5 [17], rural area of Eastern Ethiopia- 28.37 [29], Tigray, Ethiopia-62.5 [12] and
Table 4 Fetal and neonatal characteristics of the neonates admitted in Amhara region referral hospitals, Northern Ethiopia, $2018(n=612)$

\begin{tabular}{|c|c|c|}
\hline Variables & Number & Percent \\
\hline \multicolumn{3}{|l|}{ Birth weight known } \\
\hline Yes & 580 & 94.77 \\
\hline No & 32 & 5.23 \\
\hline \multicolumn{3}{|l|}{ Birth weight in $\mathrm{kg}(n=580)$} \\
\hline$<2$ & 144 & 24.83 \\
\hline $2-2.5$ & 76 & 13.10 \\
\hline $2.5-4$ & 360 & 62.07 \\
\hline \multicolumn{3}{|l|}{ Fetal presentation } \\
\hline Cephalic & 560 & 91.50 \\
\hline Breech & 48 & 7.84 \\
\hline Shoulder & 4 & 0.65 \\
\hline \multicolumn{3}{|l|}{ APGAR score known } \\
\hline Yes & 464 & 75.8 \\
\hline No & 148 & 24.2 \\
\hline \multicolumn{3}{|l|}{ APGAR score in 1st minute $(n=464)$} \\
\hline$\leq 3$ & 42 & 9.05 \\
\hline $4-6$ & 172 & 37.07 \\
\hline$\geq 7$ & 250 & 53.88 \\
\hline \multicolumn{3}{|l|}{ APGAR score in 5th minute $(n=464)$} \\
\hline $4-6$ & 103 & 22.20 \\
\hline$\geq 7$ & 361 & 77.80 \\
\hline \multicolumn{3}{|l|}{ Feeding Option } \\
\hline Exclusive breastfeeding & 568 & 92.81 \\
\hline Exclusive replacement feeding & 4 & 0.65 \\
\hline Mixed feeding & 40 & 6.54 \\
\hline \multicolumn{3}{|c|}{ Time of initiating breastfeeding $(n=608)$} \\
\hline$\leq 1 \mathrm{~h}$ & 296 & 48.68 \\
\hline$>1 \mathrm{~h}$ & 261 & 42.93 \\
\hline \multicolumn{3}{|l|}{ Gestational Age in weeks $(n=568)$} \\
\hline$<37$ wks & 208 & 33.99 \\
\hline $37 w k s-42 w k s$ & 350 & 57.19 \\
\hline$>42 w k s$ & 10 & 1.63 \\
\hline \multicolumn{3}{|l|}{ Neonatal age at admission (in hours) } \\
\hline$<24$ & 424 & 69.3 \\
\hline $24-168$ & 105 & 17.2 \\
\hline $168.1-672$ & 83 & 13.6 \\
\hline \multicolumn{3}{|l|}{ Weight at admission in $\mathrm{kg}$} \\
\hline$<2.5 \mathrm{~kg}$ & 237 & 38.7 \\
\hline$\geq 2.5 \mathrm{~kg}$ & 375 & 61.3 \\
\hline
\end{tabular}

Ethiopia-36.7 [10]. This discrepancy might be attributed to variation in study design. Unlike the current study, some previous studies were community-based [15, 17]. 


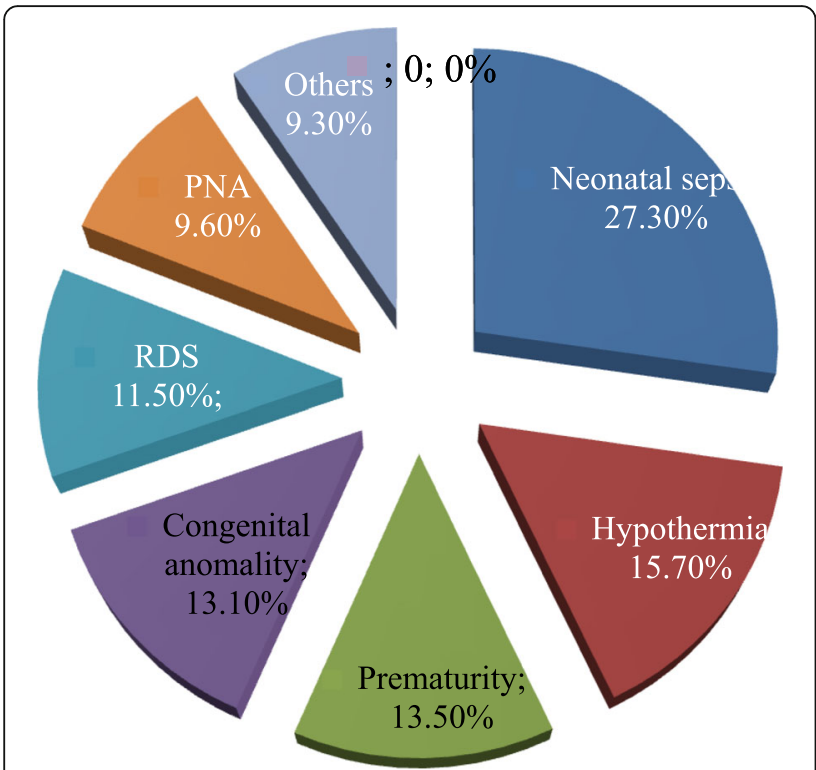

Fig. 4 Reasons for neonatal admission at NICU in Amhara region referral hospitals, Northern Ethiopia, 2018

Hence, NM tends to be lower in the community-based studies where low-risk neonates were also included in the denominator, unlike the investigations conducted in the NICU. In the studies which have been undertaken at the NICU, like the current one, the denominators are all admitted neonates (i.e. the population at higher risk for death), and it is logical that the probability of neonatal death is likely to be higher among such population than the counterparts. Moreover, the disparity in magnitude could be accredited to variation in study settings. In other words, some previous studies were conducted in developed nations [24]. Empirical evidence supports that the overall health care system, as well as the survival rate of neonates, is much better in the developed countries than in resource-limited countries [1]. The implication is ascribed to the impact of the financial barriers for receiving basic obstetric and neonatal cares in economical poor countries including Ethiopia. In connection to this, one surprising point in the current study was that about 93.79\% of respondents received at least one ANC. Similarly, more than $96 \%$ of participants gave birth at health facilities. This implies that the maternal health care service coverage was high and that was promising. However, about $52.78 \%$ of the mothers had experienced delivery complications. Moreover, nearly half $(46.12 \%)$ of the neonates had poor 1st minute Apgar score. In addition, almost all reasons for neonatal admissions and neonatal deaths were found to be preventable. This questions the quality of health care services during the perinatal period. One most probable reason for such unacceptable poor quality of maternity care and poor neonatal health outcome is delays in accessing emergency obstetric and / or neonatal cares which include delays in decision to seek care (delays at the home), delays in reaching health facilities (delays at the journey) and delays in receiving appropriate care (delays at the health facilities). One known contributing factor for such delays is financial barrier which further seems true in the current study since about four-fifth $(77.1 \%)$ of the respondents' family had earned less than 139 US dollar monthly. The costs of essential maternal and child healthcare - whether formal or informal costs - are major barriers preventing the poorest and most excluded women and children getting the services they need. User fees have been shown to be highly regressive, with a particularly negative impact on the poor, reducing uptake of essential health services. Out-of-pocket (OOP) expenditure for healthcare during pregnancy and childbirth is still common in many low- and middleincome countries. Although the country, Ethiopia, endorsed the cost-free maternal and child health care services during pregnancy and child birth processes, most of the supplies and medications are unavailable in public health facilities at the time of request. Thus, women often have to pay formal or informal charges to receive care, and have to buy their own medicines and basic necessities, such as soap and clean sheets, when going into hospital to give birth. Thus, improving transportation, strengthening referral mechanisms, assuring ambulance distribution and maintenance policies, equipping health facilities with essential supplies, mobilizing resources for $\mathrm{MNCH}$ quality improvement, availing essential reproductive health commodities, facilitating inter-sectoral collaboration to address common maternal and newborn health problems and work for adequate budget allocation for $\mathrm{MNCH}$ would decrease the high magnitude of neonatal mortality. Furthermore, the discrepancy could be attributed to variation in the scope of the study. The former neonatal mortality reports were made based on the country's aggregated findings $[1,2]$. Thus, these averaged magnitudes are expected to be lower as compared to the death incidences from referral hospitals where near-missedreferred cases are more likely to be abundant. Also, the

Table 5 Failure and survival probability of neonates admitted at NICU in Amhara region referral Hospital, $2018(n=612)$

\begin{tabular}{llllll}
\hline Time in days & Total number at the beginning & Lost & Death & Death probability (\%) with 95\% Cl & Survival probability (\%) with 95\% Cl \\
\hline $0-1$ & 612 & 44 & 64 & $10.85(8.59,13.65)$ & $89.15(86.35,91.41)$ \\
$2-7$ & 504 & 272 & 39 & $20.30(16.97,24.17)$ & $79.70(75.83,83.03)$ \\
$8-28$ & 193 & 182 & 11 & $28.89(23.57,35.12)$ & $71.11(64.88,76.43)$ \\
\hline
\end{tabular}


Table 6 Predictors of neonatal death among neonates admitted in Amhara region referral hospitals, Northern Ethiopia, $2018(n=$ 612)

\begin{tabular}{|c|c|c|c|c|}
\hline \multirow[t]{2}{*}{ Variables } & \multicolumn{2}{|c|}{ Outcome of admission } & \multirow{2}{*}{$\begin{array}{l}\text { Bivariate analysis } \\
\text { CHR with } 95 \% \mathrm{Cl}\end{array}$} & \multirow{2}{*}{$\begin{array}{l}\text { Multivariable analysis } \\
\text { AHR with } 95 \% \mathrm{Cl}\end{array}$} \\
\hline & Death n (\%) & Censored n (\%) & & \\
\hline \multicolumn{5}{|l|}{ Maternal age } \\
\hline$<35$ yrs. & $72(14.3)$ & $432(85.7)$ & 1 & 1 \\
\hline$\geq 35$ yrs & $42(38.9)$ & $66(61.1)$ & $3.82(2.03,4.35)^{*}$ & $2.60(1.44,4.72)^{*}$ \\
\hline \multicolumn{5}{|l|}{ Residence } \\
\hline Urban & $56(14.6)$ & $327(85.4)$ & 1 & 1 \\
\hline Rural & $58(25.3)$ & $171(74.7)$ & $1.98(1.27,2.66)^{*}$ & $1.22(0.66,2.25)$ \\
\hline \multicolumn{5}{|l|}{ Maternal education } \\
\hline Able to read and write & $55(13.6)$ & $350(86.4)$ & 1 & 1 \\
\hline Unable to read \& write & $59(28.5)$ & $148(71.5)$ & $2.54(1.60,3.35)^{*}$ & $1.40(1.23,2.44)^{*}$ \\
\hline \multicolumn{5}{|l|}{ Age at admission } \\
\hline Early & $111(20.98)$ & $418(79.02)$ & $7.08(2.05,20.32)^{*}$ & $2.87(0.84,9.87)$ \\
\hline Late & $3(3.61)$ & 80 (96.39) & 1 & 1 \\
\hline \multicolumn{5}{|l|}{ Cry at birth } \\
\hline No & $80(32.92)$ & $163(67.08)$ & $4.84(2.64,5.90)^{*}$ & $0.93(0.49,1.78)$ \\
\hline Yes & $34(9.21)$ & 335 (90.79) & 1 & 1 \\
\hline \multicolumn{5}{|l|}{ Number of ANC visit } \\
\hline 0 & $12(31.58)$ & $26(68.42)$ & $4.26(1.79,7.04)^{*}$ & $0.78(0.27,2.24)$ \\
\hline $1-3$ & $76(24.68)$ & $232(75.32)$ & $3.02(1.53,3.74)$ & $0.91(0.49,1.65)$ \\
\hline$\geq 4$ & $26(9.77)$ & $240(90.23)$ & 1 & 1 \\
\hline \multicolumn{5}{|l|}{ Received $\Pi T$ vaccination } \\
\hline Yes & $82(16.27)$ & $422(83.73)$ & 1 & \\
\hline No & $32(29.63)$ & $76(70.36)$ & $2.17(1.33,3.01)^{*}$ & $2.14(1.00,4.15)$ \\
\hline \multicolumn{5}{|l|}{ Type of pregnancy } \\
\hline Single-tone & $82(15.0)$ & $466(85.0)$ & 1 & 1 \\
\hline Multiple & $32(50.0)$ & $32(50.0)$ & $5.68(2.95,6.73)^{*}$ & $3.96(2 \cdot 10,7.46)^{*}$ \\
\hline \multicolumn{5}{|l|}{ Sex of neonate } \\
\hline Male & $58(15.9)$ & $307(84.1)$ & 1 & 1 \\
\hline Female & $56(22.7)$ & $191(77.3)$ & $1.55(0.96,2.01)$ & $0.76(0.48,1.19)$ \\
\hline \multicolumn{5}{|l|}{ History of stillbirth } \\
\hline No & $84(16.67)$ & $420(83.33)$ & 1 & \\
\hline Yes & $30(27.78)$ & $78(72.22)$ & $1.92(0.94,2.18)$ & $0.56(0.31,1.02)$ \\
\hline \multicolumn{5}{|l|}{ Delivery complication } \\
\hline No & $22(7.6)$ & $267(92.4)$ & 1 & 1 \\
\hline Yes & $92(28.5)$ & $231(71.5)$ & $4.83(2.47,6.30)^{*}$ & $1.30(0.68,2.48)$ \\
\hline \multicolumn{5}{|l|}{ Neonatal sepsis } \\
\hline No & $86(23.1)$ & $286(76.9)$ & 1 & 1 \\
\hline Yes & $103(42.92$ & $137(57.08)$ & $2.50(1.81,5.27)^{*}$ & $0.69(0.49,1.19)$ \\
\hline \multicolumn{5}{|l|}{ Fetal presentation } \\
\hline Cephalic & $95(17.0)$ & $465(83.0)$ & 1 & 1 \\
\hline Non-Cephalic & $19(36.5)$ & $33(63.5)$ & $2.82(1.61,4.33)^{*}$ & $1.08(0.58,2.02)$ \\
\hline
\end{tabular}


Table 6 Predictors of neonatal death among neonates admitted in Amhara region referral hospitals, Northern Ethiopia, $2018(n=$ 612) (Continued)

\begin{tabular}{|c|c|c|c|c|}
\hline \multirow[t]{2}{*}{ Variables } & \multicolumn{2}{|c|}{ Outcome of admission } & \multirow{2}{*}{$\begin{array}{l}\text { Bivariate analysis } \\
\text { CHR with } 95 \% \mathrm{Cl}\end{array}$} & \multirow{2}{*}{$\begin{array}{l}\text { Multivariable analysi } \\
\text { AHR with } 95 \% \mathrm{Cl}\end{array}$} \\
\hline & Death n (\%) & Censored n (\%) & & \\
\hline \multicolumn{5}{|c|}{ Mother HIV status } \\
\hline Negative & $106(17.8)$ & $491(82.2)$ & 1 & 1 \\
\hline Positive & $8(53.3)$ & $7(46.7)$ & $5.29(2.24,5.36)^{*}$ & $6.57(2.53,17.06)^{*}$ \\
\hline \multicolumn{5}{|l|}{ Parity } \\
\hline 1 & $32(12.2)$ & $231(87.8)$ & $0.49(0.36,0.86)^{*}$ & $1.12(0.62,1.98)$ \\
\hline $2-4$ & $59(21.9)$ & $211(78.1)$ & 1 & 1 \\
\hline$\geq 5$ & $23(29.1)$ & $56(70.9)$ & $1.47(0.87,2.28)$ & $1.17(0.56,2.44)$ \\
\hline
\end{tabular}

dissimilitude in mortality might be ascribed to variation in parent's socio-demographic characteristics.

On the other hand, the magnitude of NMR in the current study is lower as compared to the findings of the studies done at University of Gondar referral hospital252 [30], Paul's Hospital Millennium Medical College Addis Ababa- 232 [31], Pakistan Health Survey of 2014680 [32] and University of Gondar comprehensive Specialized hospital (UoGCSH) - 288 [33]. The variation in the magnitude of NMR could be secondary to the difference in the scope of the study. It is observed that some other previous studies were conducted in a single centered institution which might have lacked representativeness unlike the current one [30, 31, 33]. The disparity also could be linked to discrepancy in sample size. In the former study conducted in Addis Ababa, the sample size was 216 which accounts only nearly one-third of the current one [31]. The difference in magnitude also might be related to respondent's residency. In the previous study, about seven-tenths (70\%) of the respondents were rural dwellers which is much greater than that of in the current study [32]. In this perspective, evidences exhibit that neonatal mortality tends to be higher among rural residents [34, 35]. This could be rationalized as rural residents usually could not get access to health-related information easily and health care services timely as equal as urban residents. Besides, the dissimilarity in NMR extent might be secondary to variation in the study population. Unlike the current study which recruited all admitted neonates disregard to their gestational age, some previous studies had entailed only preterm neonates $[30,33]$. In connection to this, studies indicate that the risk of neonatal death is higher among preterm neonates than among term neonates [31, 36].

The current study exhibits that the overall cumulative survival probability of neonates at the end of the follow-up period was $71.11 \%$. This result is lower as compared to the findings of a previous study done in Tigray, northern Ethiopia 93.96\% [12]. This variation in survival probability of neonates might arise from the difference in the study population. In the former study, all live births (i.e. all alive neonates) had been recruited, whereas only admitted neonates (i.e. population at high risk) had involved in the current one. Thus, the survival probability is more likely to be higher among all live births than that of neonates admitted with some problems.

On the contrary, the survival probability of neonates in the current study is higher as compared to that of the study carried out at UoGCSH (57.14\%) [33]. This dissimilarity might be accredited to variation in study population again. Accordingly, the study population in the previous study was premature neonates that pose a higher probability of death as compared to that of in the current study (i.e. all neonates irrespective of gestational age).

This study also shows that the cumulative survival probability of neonates at the end of the first day was $89.15 \%$. This is lower than the previous study done at UoGCSH where the cumulative survival probability over $24 \mathrm{~h}$ was 96.71\% [33]. As far as the result of these two studies compared, some sort of surprising findings are observed. In the first $24 \mathrm{~h}$, the survival probability of neonates in the former study (96.71\%) was higher than that of the current one $(89.15 \%)$. Thereafter, the survival probability in the early neonatal period and overall cumulative period comes to be lower in the previous study (74.62 and $57.14 \%$ respectively) as compared to the current study (79.70 and $71.11 \%$ respectively). This implies that the probability of death among study population in a previous study (i.e. premature neonates) has highly increased as neonatal age advanced than that of the general admitted neonates.

In the current study, it was observed that the risk of death among neonates born to mothers with advanced age is more than two times higher as compared to their counterparts. This finding is also supported by other studies conducted in Sudan [15] and Suriname [24]. This could be related to the evidence-based facts that advanced maternal age is associated with certain pregnancy-related risks including poor neonatal outcome [37]. Therefore, efforts need to be collaborated to minimize the risky conditions such as pregnancy at advanced maternal age. 
In many circumstances, maternal educational status matters obstetric and perinatal outcomes [10]. Studies indicated that the outcome of pregnancy among educated women is more likely to be better than among uneducated ones [38]. The current study had come up with findings which support this fact. Accordingly, the risk of death for neonates born to mothers who are unable to read and write was 1.40 times higher as compared to those neonates whose mothers can read and write. This aligns with the findings of previous studies done in different settings in Ethiopia [10, 34]. This could be explained by the role of education on the maternal level of apprehensive. Accordingly, educated mothers have a better awareness of the healthcare-related information and thus, might behave and act as per the standard of health care service utilization in a symphonious manner with their caregiver. Moreover, educated mothers are more likely to search health-related information in a variety of other ways such as by attending mass media, browsing internets and reading magazines. Consequently, they are likely to evolve with accurate health-related information enough to make appropriate decisions and to take corrective actions even in the emergency. Surprisingly, nearly two-fifth (38.72\%) of the respondents in the current study had never attended any formal education at the time of interview. Meanwhile, being unable to read and write exhibited to be the independent predictor of neonatal mortality. The finding implies that all stakeholders need to work more on the gender inclusive education policy which promotes all females to be engaged in formal education. Similarly, about $40.81 \%$ of fathers of neonates had never been educated through formal education. Hence, the finding also entails the need of information, education, and communication to improve the community awareness of neonatal death risk factors and danger signs.

Also, neonates born to HIV positive mothers were 6.57 times more likely to die during the neonatal period as compared to those born to sero-negative mothers. This is following a systematic review study [8]. This is also in line with a study conducted at University of Gondar Referral Hospital, Ethiopia [30]. This might be related to the effect of HIV infection on the maternal overall health condition. And it is evidence-based fact that the fetal health condition is directly or indirectly influenced by maternal health status [39]. In other words, the maternal and fetal general condition is strongly interlinked to each other. Thus, if the maternal immunity and other conditions are compromised by HIV infection, the fetal health condition would be endangered too, which the jeopardized fetal health condition would more likely lead to neonatal death. The finding, herein, suggests that offering integrated PMTCT services to $\mathrm{MNCH}$ programs would decrease neonatal mortality rate. The result also further alerts the health care providers to be vigilant enough to screen, diagnose and treat maternal infections. According to the current study finding, the risk of neonatal mortality is more than three times higher in multiple pregnancies than single tones. This finding is supported by previous studies done in different settings [17, 19, 26, 30, 40]. This could be attributed to the effect of multiple pregnancies in life-threatening perinatal outcomes. Multiple pregnancies usually carry a higher risk of prematurity, premature rupture of membrane, abnormal presentation and amniotic fluid abnormality and IUGR which all may increase the probability of neonatal death [41-43]. Hence, as multiple gestations is one of the high risk pregnancies and is an independent predictor of neonatal death, it demands close monitoring and care.

\section{Limitations}

This study recruited all admitted neonates who were at higher risk of death. Thus, the NMR reported from this study could be overestimated as compared to other reports made by taking all live births as a denominator. In this study, the measurement of some variables might have been committed to recall bias. Of course, we had executed certain efforts to minimize such potential recall biases. First, the questionnaire had been well devised in such a way that it was structured from simple to complex and recent to past in chronological order. It was also translated to local language. In addition, we had evaluated the tool by conducting a pretest prior to the actual data collection. Second, we had delivered trainings for the data collectors and supervisors on the strategies of minimizing recall bias. Thus, the interviewers had been told to assure that each question is clearly understood by the respondents before the responses, to inform the local events that may trigger the respondents' recalling capacity, to give participants sufficient time to recall long term memory, to verify with any record or any other potential source of information such as family members, intimate friends and any other persons who were around at the time of event, and to use multiple source of information like crosschecking the documented records and contacting the concerned health care providers for uncertainties in documentations.

\section{Conclusion}

The neonatal mortality incidence rate in the study setting was higher than the national figure, and the highest probability of neonatal deaths has been recorded in the early neonatal period. Advanced maternal age, uneducated maternal status, positive maternal HIV status, and multiple pregnancies were the independent predictors for neonatal mortality. Thus, stakeholders need to consider the distinguished risky time and the identified independent risk factors of neonatal death while they design strategies to reduce the high mortality rate. 


\section{Abbreviations}

AHR: Adjusted Hazard Ratio; ANC: Ante-Natal Care; APGAR: Appearance, Pulse, Grimes Activity and Respiratory; C/S: Cesarean Section; CHR : Crude Hazard Ratio; Cl: Confidence Interval; EDHS : Ethiopia Demographic Health Survey; HIV: Human Immunodeficiency Virus; HR: Hazard Ratio; IDM : Infants of Diabetes Miletus; IQR: Inter Quartile Range; MAS: Meconium Aspiration Syndrome; MOH: Minister of Health; NICU: Neonatal Intensive Care Unit; NM: Neonatal Mortality; NMIR: Neonatal Mortality Incidence Rate; NMR: Neonatal Mortality Rate; PNA : Perinatal Asphyxia; PROM: Premature Rupture of Membrane; RDS: Respiratory Distress Syndrome; SD: Standard Deviation; SDG : Sustainable Development Goal; SGA: Small For Gestational Age; TT: Titanus Toxoid; UNICEF: United Nations International Children's Emergency Fund; UoGCSH: University of Gondar Comprehensive Specialized Hospital

\section{Acknowledgments}

We would like to thank School of Midwifery, College of Medicine and Health Sciences, University of Gondar and Amhara Region Health for their support. We also like to forward our deepest and sincere appreciation to all data collectors and study participants.

\section{Authors' contributions}

BAM: designed the study, performed analysis and interpretation of data and developed and revised the manuscript. AEY, ZNA \& MSM: designed and approved the proposal with some revisions, participated in data analysis, revised subsequent drafts of the paper, and revised the manuscript. All authors read and approved the final draft of the manuscript.

\section{Funding}

The authors have also declared that no financial support in the research, authorship, and publication of this article was received.

\section{Availability of data and materials}

While ethics statement has been stated, we have agreed and signed in order not to publish the raw data retrieved from the information of the mothers. However, the data sets collected and analyzed for the current study are available from the corresponding author and can be obtained on a reasonable request.

\section{Ethics approval and consent to participate}

The ethical clearance was obtained from the School of Midwifery, College of Medicine and Health Sciences on behalf of Institutional Review Board of the University of Gondar. Permission was obtained from Amhara Regional Health Bureau which wrote a supportive letter to the respective hospitals' directorate office. Written Informed Consent of the respondents was then obtained after a brief provision of information on the aim, risk and benefits, and the rights. All participants were informed that they can have the right to refuse at any stage of data collections. Confidentiality and privacy issues had been also assured.

\section{Consent for publication}

Not applicable.

\section{Competing interests}

The authors declare that they have no competing interests.

\section{Author details}

${ }^{1}$ Teda Health Science College, Amhara Regional Health Bureau, Department of Midwifery, Po. Box 196, Gondar, Ethiopia. ${ }^{2}$ Department of Clinical Midwifery, School of Midwifery, College of Medicine and Health Sciences, University of Gondar, Gondar, Ethiopia. ${ }^{3}$ Department of Women's and Family Health, School of Midwifery, College of Medicine and Health Sciences, University of Gondar, Gondar, Ethiopia.

Received: 14 August 2019 Accepted: 12 March 2020 Published online: 01 April 2020

\section{References}

1. UNICEF, <SOWC-Statistical-Tables-2017.pdf>. http://www.unicef.org/sowc. 2018.
2. ICF, et al., Ethiopia Demographic and Health Survey. http://www DHSprogram.com. 2016.

3. Ezeh OK. Trends and population-attributable risk estimates for predictors of early neonatal mortality in Nigeria. BMJ. 2017;7(7):013350.

4. Oestergaard MZ, et al. Neonatal mortality levels for 193 countries in 2009 with trends since 1990: a systematic analysis of progress, projections, and priorities. PLoS Med. 2011:8:8.

5. Trana HT, et al. A systematic review of the burden of neonatal mortality and morbidity in the ASEAN region. WHO South-East Asia J Public Health. 2012; 1(3):239-48.

6. Sankar MJ, et al. When do newborns die? A systematic review of timing of overall and cause-specifi c neonatal deaths in developing countries. J Perinatol. 2016;36:S1-S11.

7. Akinyemi JO, Bamgboye EA, Ayeni O. Trends in neonatal mortality in Nigeria and effects of bio-demographic and maternal characteristics. BMC Pediatr. 2015;15(1):36

8. Liu L, et al. Global, regional, and national causes of child mortality in 200013 , with projections to inform post-2015 priorities: an updated systematic analysis. Lancet. 2015;385(9966):430-40.

9. WHO. Sustainable development goal 3. Gütersloh: WHO Reginal Office; 2015. http://www.who.int/sdg/targets/en/.

10. Mekonnen $Y$, et al. Neonatal mortality in Ethiopia: trends and determinants. BMC Public Health. 2013;13:483.

11. Federal Ministry of Health. Mini demographic and health survey 2019 key indicators. Rockville: The DHS Program ICF; 2019. https://dhsprogram.com. pubs.pdf.

12. Mengesha $\mathrm{HG}$, et al. Survival of neonates and predictors of their mortality in Tigray region, NorthernEthiopia. BMC Pregnancy Childbirth. 2014;16(1):202.

13. $\mathrm{MOH}$. The Federal Democratic Republic of Ethiopia Ministry of Health. Health sector transformation plan; 2015

14. Onasoga Olayinka A, Oluwatosin AO, Ojo Adeleke A. Predictors of Neonatal Morbidity and Mortality. (USA) AASRC9; 2012. http://scholarsresearchlibrary. com/archive.html.

15. Bashir AO, et al. Neonatal mortality in Sudan. BMC Public Health. 2013;13:287.

16. Li C, et al. Predictors for neonatal death in the rural areas of Shaanxi Province of northwestern China. BMC Public Health. 2010;15(1):387.

17. Debelew GT, Afework MF, Yalew AW. Determinants and causes of neonatal mortality in JimmabZone, Southwest Ethiopia. PLoS One. 2013;9(9):107184.

18. Kassar SB, et al. Determinants of neonatal death with emphasis on health care during pregnancy, childbirth and reproductive history. J Pediatr. 2013; 89(3):269-77.

19. Haghighi L, et al. Survival predictors of preterm neonates: hospital based study in Iran. Iran J Reprod Med. 2013;11(12):957-64.

20. ICF C. Ethiopia demographic and health survey. Addis Ababa: CSA and ICF; 2016. http://www.DHSprogram.com.

21. Negash MA, Elazar T. Perinatal death and associated factors in Wolaita Sodo referral hospital. Prim Health Care. 2017;7(269):2167.

22. Ndombo PK, et al. A cohort analysis of neonatal hospital mortality rate and predictors of neonatal mortality in a sub-urban hospital of Cameroon. Ital J Pediatr. 2017;43(1):52.

23. Wang $\mathrm{C}-\mathrm{H}$, et al. Analysis of in-hospital neonatal death in the tertiary neonatal intensive care unit in China: a multicenter retrospective study. Chin Med J. 2016:129(22):2652-8.

24. Zijlmans W, Hindori-Mohangoo A. Determinants of neonatal mortality in Suriname: preliminary findings from a perinatal and infant mortality survey. Ann Glob Health. 2015;81(1):121-2.

25. Anggondowati T, et al. Maternal characteristics and obstetrical complications impact neonatal outcomes in Indonesia. BMC Pregnancy Child. 2017;17:100.

26. Diallo $\mathrm{AH}$, et al. A prospective study on neonatal mortality and its predictors in a rural area in Burkina Faso. J Perinatol. 2011;31:656-63.

27. Farah $A E$, Abbas $A H$, Ahmed AT. Trends of admission and predictors of neonatal mortality: a hospital based retrospective cohort study in Somali region of Ethiopia. PLoS One. 2018;13:9

28. Roba AA, Diro DH. Morbidities, rate and Time Trends of Neonatal Mortality in Dilchora Referral Hospital, Dire Dawa, Ethiopia, 2012-2017. Austin Med Sci. 2017;2:1.

29. Desta BN, et al. Neonatal mortality and its risk factors in eastern Ethiopia: a prospective cohort study in Kersa health and demographic surveillance system (Kersa HDSS). Epidemiol Biostat Public Health. 2016;13:4.

30. Yehuala S, Ayalew S, Teka Z. Survival analysis of premature infants admitted to neonatal Int ensive care unit (NICU). Biometrics Biostat. 2015;6:1. 
31. Tekleab, et al. Reasons for admission and neonatal outcome in the neonatal care unit of a tertiary care hospital in Addis Ababa: a prospective study. Res Rep Neonatology. 2016;6:17-23.

32. Nisar YB, Dibley MJ. Determinants of neonatal mortality in Pakistan. BMC Pregnancy Child. 2014;14:663.

33. Yismaw AE, Gelagay AA, Sisay MM. Survival and predictors among preterm neonates admitted at University of Gondar comprehensive specialized hospital neonatal intensive care unit, Northwest Ethiopia. Ital J Pediatr. 2019: 45:4.

34. Berhanu Teshome Woldeamanuel. Statistical analysis of neonatal mortality: a case study of Ethiopia. J Pregnancy Child Health. 2018;5:2

35. Shah $\mathrm{R}$, et al. Factors associated with neonatal deaths BMC pregnancy and child; 2015.

36. Ishtiyaq Q, Aijaz AM, Qazi I. Clinicoepidemiological profile and predictors of mortality in LBW babies. Neonatal Pediatr Med. 2016;2(119):2.

37. Mutz-Dehbalaie, et al. Perinatal mortality and advanced maternal age. Gynecol Obstet Investig. 2014;77(1):50-7.

38. Fonseca SC, Flores PVG, Coeli CM. Maternal education and age: inequalities in neonatal death. Rev Saude Publica. 2017:51:94

39. Wedi $\mathrm{CO}$, et al. Perinatal outcomes associated with maternal HIV infection: a systematic review and meta-analysis. Lancent HIV. 2016;3(1):33-48.

40. Kayode GA, et al. Individual and community determinants ofneonatal mortality in Ghana. BMC pregnancy and child. 2014;14(1):165.

41. Dudenhausen JW, Maier RF. Perinatal problems in multiple births. Dtsch Arztebl Int. 2010;107(38):663-8.

42. Ri-Na S, et al. Materna I and neonatal outcomes in multiple pregnancy: a multicentre study in the Beijing population. Chron Dis Transl Med. 2015; 1(2015):197-202.

43. Marete I, et al. Perinatal outcomes of multiple gestation pregnancies in Kenya, Zambia, Pakistan, India, Guatemala and Argentina: a global network study. Am J Perinatol. 2015;31 (2):125-32.

\section{Publisher's Note}

Springer Nature remains neutral with regard to jurisdictional claims in published maps and institutional affiliations.

Ready to submit your research? Choose BMC and benefit from:

- fast, convenient online submission

- thorough peer review by experienced researchers in your field

- rapid publication on acceptance

- support for research data, including large and complex data types

- gold Open Access which fosters wider collaboration and increased citations

- maximum visibility for your research: over $100 \mathrm{M}$ website views per year

At BMC, research is always in progress.

Learn more biomedcentral.com/submissions 